\title{
Keloid-like dermatofibroma
}

\section{Fatima Azzahra El Gaitibi', Soumaya Hamich', Asmae Abdelmoutalib', Kaoutar Znati², Mariame Meziane ${ }^{1}$, Badereddine Hassam ${ }^{1}$, Karima Senouci ${ }^{1}$} ${ }^{1}$ Department of Dermatology, Mohammed V University in Rabat, Ibn Sina University Hospital, Rabat. Morocco, ${ }^{2}$ Department
of Histopathology, Mohammed V University in Rabat, Ibn Sina University Hospital, Rabat. Morocco

Corresponding author: Fatima Azzahra El Gaitibi, MD, E-mail: elgaitibi.fatimaazzahra@gmail.com

Dermatofibroma is a common benign skin tumor, mainly occurring in young to middle-aged females. It is frequently localized in the lower extremities. A typical dermatofibroma usually presents itself as a single firm papule or nodule, of variable color, bluish, brownish, or pinkish. Its clinical, dermoscopic, and histological features usually allow easy diagnosis [1]. However, it is possible to observe some variations of these typical features. Keloid-like dermatofibroma is one of these atypical presentations rarely reported in the literature [2].

A 40-year-old patient with no previous medical history presented to our dermatology department with a lumbosacral lesion evolving for several months. A physical examination revealed a firm, well-demarcated, asymptomatic erythematous nodule, $5 \times 12 \mathrm{~mm}$ in size, localized in the lumbosacral area (Fig. 1). The patient denied any trauma preceding the onset of the lesion. There was no personal or familial history of keloidal scars. A dermoscopic examination revealed erythema, telangiectatic vessels, a shiny white streak, and a brownish-yellow pigmentation (Fig. 2). A biopsy was performed. A histological examination revealed an atrophic epidermis. The dermis contained a fibroblastic proliferation of low cell density haphazardly arranged, located on a fibromatous background (Figs. 3 and 4). Dermatofibroma with a keloidal presentation was the diagnosis.

In the present case, dermoscopic features were different from the signs usually found in dermatofibroma, which are a central white patch and a delicate pigment network. Indeed, a keloidal-like dermatofibroma presents itself as a pink nodule with other dermoscopic

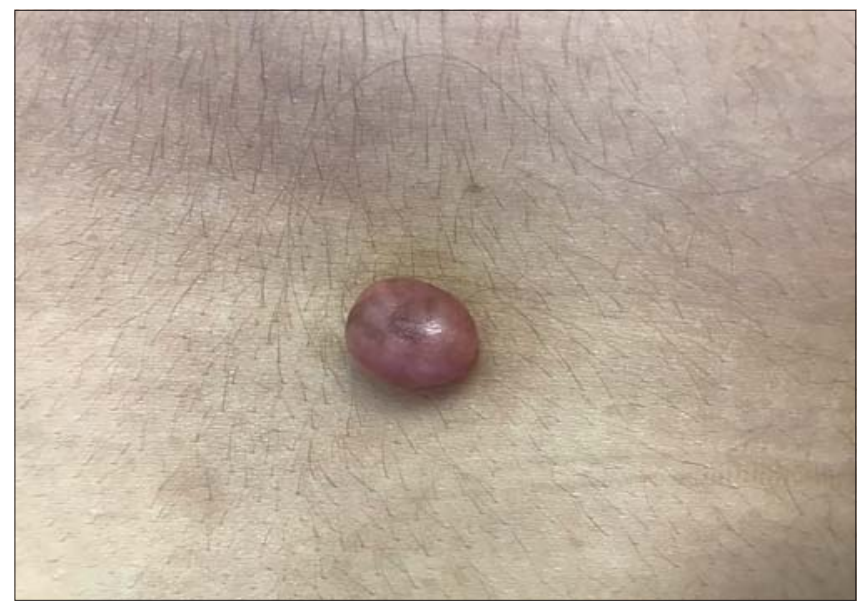

Figure 1: The firm erythematous nodule in the lumbosacral area.

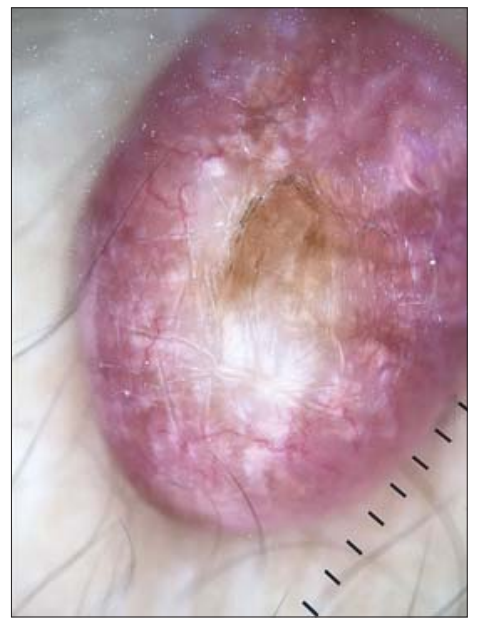

Figure 2: Erythema, telangiectatic vessels, a shiny white streak, and a brownish-yellow pigmentation.

features. Erythema and vascular structures (arborizing vessels or/and dotted vessels) are the most frequently reported features. Besides, the shiny white streaks are

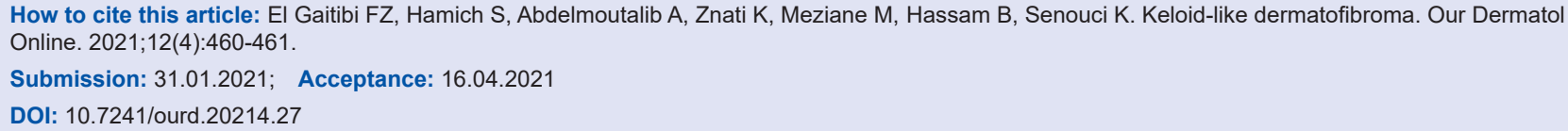


www.odermatol.com

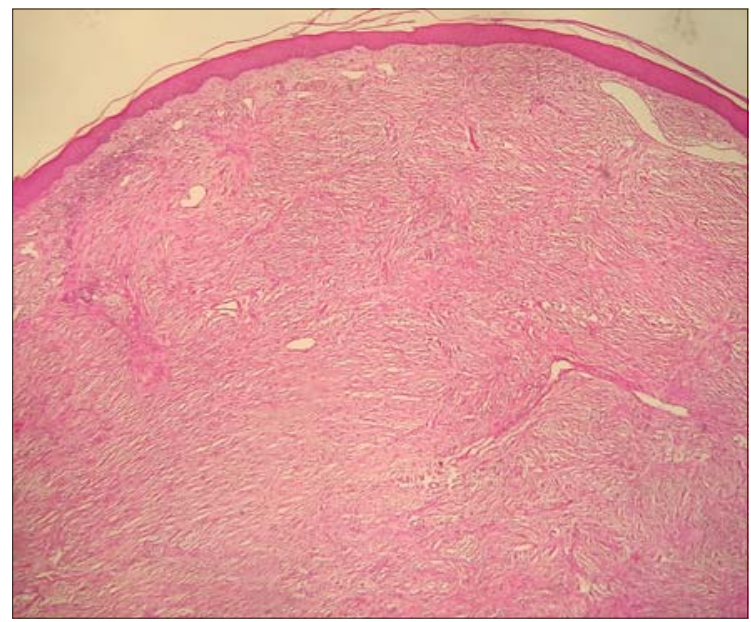

Figure 3: An atrophic epidermis and a fibroblastic proliferation on a fibromatous background (H\&E; 10x).

present in around half of cases. These features may be suggestive of malignant lesions, especially amelanotic melanoma and basal cell carcinoma [3]

\section{Consent}

The examination of the patient was conducted according to the principles of the Declaration of Helsinki.

The authors certify that they have obtained all appropriate patient consent forms, in which the patients gave their consent for images and other clinical information to be included in the journal. The patients understand that their names and initials will not be published and due effort will be made to conceal their identity, but that anonymity cannot be guaranteed.

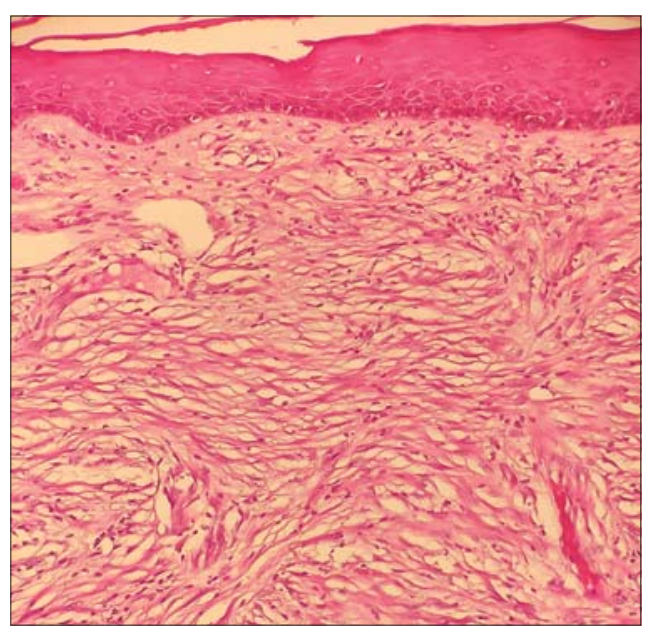

Figure 4: A fibroblastic proliferation of low cell density haphazardly arranged, located on a fibromatous background (H\&E; 40X).

\section{REFERENCES}

1. Ben Rejeb S, Dhaoui A, Ben Ghachem D, Souissi A, Bellil K. Multiple eruptive dermatofibromas occuring in a patient under hemodialysis. Our Dermatol Online. 2016;7:412-4.

2. Kim JM, Cho HJ, Moon SH. Rare experience of keloidal dermatofibroma of forehead. Arch Craniofac Surg. 2018;19:72-4.

3. Llambrich A, Vila A, Terrasa F, Bañuls J, Nadal C, Zaballos P. Dermoscopy of pink nodular dermatofibromas: A study of 36 cases. Australas J Dermatol. 2019;60:e357-60.

Copyright by Fatima Azzahra El Gaitibi, et al. This is an open access article distributed under the terms of the Creative Commons Attribution License, which permits unrestricted use, distribution, and reproduction in any medium, provided the original author and source are credited.

Source of Support: Nil, Conflict of Interest: None declared. 